\title{
Leaching studies on borosilicate glasses for the immobilization of high-level radioactive waste in the pellet form subjected to aggressive test conditions
}

\author{
VIDYA S THORAT ${ }^{1,2}$, R K MISHRA $^{1}$, V SUDARSAN ${ }^{3}$, AMAR KUMAR ${ }^{1}$, A K TYAGI $^{2,3}$ \\ and C P KAUSHIK ${ }^{1,2, *}$ \\ ${ }^{1}$ Waste Management Division, Bhabha Atomic Research Centre, Mumbai 400085, India \\ ${ }^{2}$ Homi Bhabha National Institute, Anushakti Nagar, Mumbai 400094, India \\ ${ }^{3}$ Chemistry Division, Bhabha Atomic Research Centre, Mumbai 400085, India \\ *Author for correspondence (cpk@barc.gov.in)
}

MS received 29 January 2019; accepted 26 March 2019

\begin{abstract}
Pellet leaching and associated thermal and structural changes of sodium borosilicate (NBS) glass, used for the immobilization of high-level radioactive liquid waste, subjected to aggressive test conditions have been compared with international simple glass (ISG) subjected to the same leaching conditions. The crystalline phase getting separated out from NBS glass is found to be different for pellets and powder leaching experiments and this has been explained based on the difference in the extent of leaching occurring with glass samples in the two experiments. Based on Fourier transform infrared studies, it is inferred that, unlike in the ISG sample, $\mathrm{Si}-\mathrm{O}-\mathrm{Si} / \mathrm{B}$ structural units become more ordered with the leaching in the case of NBS glass, and this is attributed to the partial network destruction occurring with NBS glass and crystallization of the $\mathrm{SiO}_{2}$ phase from the glass matrix. Both the NBS glass and ISG sample show L-centre emission and the emission intensity remained unaffected with leaching, confirming that the local environment around non-bridging oxygen atoms in the NBS glass and ISG sample are unaffected and leaching occurs through network dissolution.
\end{abstract}

Keywords. Borosilicate glass; leaching; ISG; FTIR; DTA; luminescence.

\section{Introduction}

A vitrification process is being adopted for the immobilization of high-level radioactive liquid waste generated from spent nuclear fuel reprocessing plants, in countries like France, Japan, India and UK [1-4]. The most extensively studied and widely used waste form for vitrification is borosilicate glasses [4-7]. Leaching properties of such glass matrices under different environments are of prime importance and concern, while deciding the glass composition for the above-mentioned application. Water is the most common component present in different environments and hence the nature of interaction of water with glass is of significant interest among different groups working on borosilicate glasses. The interaction of glass with water involves three steps [8-11], namely, diffusion of water molecules into glass followed by ion exchange with protons and network-modifying ions in the glass. Hydrolysis of the network (silica, alumina, borate, etc.) and the subsequent breakdown of the glass network is the second step. In the third step, precipitation or formation of passive layers on the surface of glass is expected to occur eventually attaining the residual leach rate [9]. The leaching properties of sodium borosilicate (NBS) glasses containing different additives have been investigated in detail [8-11]. For example, Gin et al [12] observed that in borosilicate glass containing $\mathrm{Ca}^{2+}$,
$\mathrm{Al}^{3+}$ and $\mathrm{Zr}^{4+}$, a synergic effect operates between $\mathrm{Ca}^{2+}$ and $\mathrm{Al}^{3+}$ or $\mathrm{Zr}^{4+}$ which reduces the residual leach rate of glass. Similarly, $\mathrm{Zr}^{4+}$ containing glasses are found to be more resistant to the leaching of alkali metal ions [13]. Extensive studies on the physico-chemical properties of both NBS and barium sodium borosilicate (BBS) glasses containing different additives like sulphates, fluorides, $\mathrm{Cs}_{2} \mathrm{O}, \mathrm{TiO}_{2}, \mathrm{BaO}, \mathrm{CaO}$, $\mathrm{ZnO}$, etc. [14-16] were earlier investigated in our group. A correlation between structural units present in the glass and physico-chemical properties has been arrived in some of the above-mentioned studies.

It is worth mentioning here that for a better understanding and consensus among researchers, on the mechanism and kinetics of corrosion processes associated with the leaching of borosilicate glasses, the waste glass community has developed an international simple glass (ISG) $[17,18]$ based on six oxide components. Gin et al [17] have carried out detailed static leaching studies on this simple glass at $\mathrm{pH}$ values 9.0 and 11.5 and confirmed the formation of alteration layers on the glass surface due to the release of weakly bonded cations like $\mathrm{Na}^{+}, \mathrm{Ca}^{2+}$ and boron species. Our studies also include the evaluation of the leaching properties of the in-house developed NBS and BBS glasses in detail [19] and their comparison with that of ISG samples. 
Most of the leaching studies were carried out on glass samples in the powder form with a specific surface area. The vitrified waste product will initially be in the monolithic form; therefore, it is prudent to study the leaching behaviour of different glasses in the pellet form. As the surface area of the pellet samples are in general lower than that of powder samples, the extent of leaching, $\mathrm{pH}$ of the leached solution, crystalline phase formed, etc. are quite different from that of glass samples subjected to powder leaching studies. Such factors can also affect the leach rates and residual leach rates. Keeping this in mind, the pellet leaching properties of the inhouse developed NBS glass under aggressive test conditions (at a temperature of $200^{\circ} \mathrm{C}$ and under a pressure of $\sim 16$ bar) have been evaluated and compared with that of the ISG samples. Under the above-mentioned experimental conditions due to the increased reactivity of water molecules, significant changes can occur with the glass in a short time duration which will be helpful for predicting glass properties (leaching) under normal conditions for long time durations. In the present study, structural changes occurring with glasses in pellet shapes subjected to leaching under aggressive conditions have been investigated using X-ray diffraction (XRD), differential thermal analysis (DTA), Fourier transform infrared (FTIR) spectroscopic and photoluminescence techniques. To the best of our understanding, this is the first time we report a comparative study on the pellet leaching properties of NBS glass and ISG.

\section{Experimental}

\subsection{Glass preparation}

Starting materials for the preparation of NBS glass are AR grade sodium nitrate, silica, boric acid, calcium nitrate, titanium dioxide and aluminium nitrate. The constituents and their relative amounts taken for the preparation of $\sim 100 \mathrm{~g}$ of NBS glass are: $\mathrm{SiO}_{2}(47.7 \mathrm{~g}), \mathrm{H}_{3} \mathrm{BO}_{3}$ (42.46 g), $\mathrm{NaNO}_{3}$ $(46.614 \mathrm{~g}), \mathrm{Ca}\left(\mathrm{NO}_{3}\right)_{2} \cdot 4 \mathrm{H}_{2} \mathrm{O}(28.65 \mathrm{~g}), \mathrm{TiO}_{2}(2.3 \mathrm{~g})$ and $\mathrm{Al}\left(\mathrm{NO}_{3}\right)_{3} \cdot 9 \mathrm{H}_{2} \mathrm{O}(16.912 \mathrm{~g})$. The compounds were mixed, ground thoroughly and heated at $1000^{\circ} \mathrm{C}$ for $4 \mathrm{~h}$ in a platinum crucible. The free flowing melt obtained was quenched between two stainless steel plates [20]. The tentative composition of glass samples [19] has been calculated from initial amounts of constituents taken for glass preparation and found to be $\left(\mathrm{SiO}_{2}\right)_{0.477}\left(\mathrm{~B}_{2} \mathrm{O}_{3}\right)_{0.239}\left(\mathrm{Na}_{2} \mathrm{O}\right)_{0.170}\left(\mathrm{TiO}_{2}\right)_{0.023}$ $(\mathrm{CaO})_{0.068}\left(\mathrm{Al}_{2} \mathrm{O}_{3}\right)_{0.023}$. The ISG sample with the composition $\left(\mathrm{SiO}_{2}\right)_{0.601}\left(\mathrm{~B}_{2} \mathrm{O}_{3}\right)_{0.160}\left(\mathrm{Na}_{2} \mathrm{O}\right)_{0.126}(\mathrm{CaO})_{0.057}\left(\mathrm{Al}_{2} \mathrm{O}_{3}\right)_{0.038}$ $\left(\mathrm{ZrO}_{2}\right)_{0.017}$ was used as received.

\subsection{Leaching experiments}

Glass samples in the cylindrical form were obtained by pouring glass melt into a preheated graphite mould. The glass cylinders were sliced into pellets with a diameter of $1.15 \mathrm{~cm}$ and a height of $0.15 \mathrm{~cm}$ using a low-speed cutter with a diamond blade. The glass pellets were mixed with $100 \mathrm{ml}$ demineralized water in a Teflon-lined autoclave made of stainless steel. The $\mathrm{pH}$ of the water was maintained at 6.2. The autoclave was then heated to $200^{\circ} \mathrm{C}$ for $192 \mathrm{~h}$ and at a pressure of $\sim 16$ bar. After completion of the experiment, the leachant was filtered through a $0.45 \mu \mathrm{m}$ syringe filter. Concentrations of different elements leached out into the solution were determined using an inductively coupled plasma atomic emission spectrometer (ICP-AES, model ULTIMA-2 from Horiba, Jobin Yvon).

The normalized release rate with respect to a particular element ' $i$ ' from the glass $\left(\mathrm{NR}_{i}\right)$ has been calculated based on equation (1):

$$
\mathrm{NR}_{i}=\frac{C_{i}}{\left(f_{i}\right)(S A / V)(t)},
$$

where $C_{i}$ is the concentration of element ' $i$ ' in the solution with the unit ' $\mathrm{g} \mathrm{l}^{-1}$ ' and ' $f_{i}$ ' is the fraction of element ' $i$ ' in the unleached glass (a unitless parameter). The term ' $S A$ ' represents the surface area of the glass piece $\left(\mathrm{m}^{2} \mathrm{~g}^{-1}\right)$ and $V$ represents the leachate volume $(L)$. The duration of leaching is represented by the term ' $t$ ' with the unit of day.

\subsection{Characterization}

The chemical composition of glass was ascertained using ICPAES. For this purpose, a known amount of glass powder was fused with sodium carbonate at $1100^{\circ} \mathrm{C}$ in a platinum crucible. The mass was dissolved in nitric acid. The dissolved solution was then analysed for $\mathrm{Si}, \mathrm{B}, \mathrm{Na}, \mathrm{Al}, \mathrm{Ti}$ and $\mathrm{Ca}$. The values obtained are in good agreement with the nominal chemical composition of the glass with an uncertainty of 2 atom\%. XRD patterns were recorded with a Philips PW1710 diffractometer with $\mathrm{Ni}$-filtered $\mathrm{CuK} \alpha$ radiation. FTIR measurements were carried out on a Bomem (MB102) spectrometer. Prior to IR measurements, samples were powdered with dry $\mathrm{KBr}$ and made in the form of a thin pellet and mounted inside the sample chamber. Emission, excitation and lifetime measurements were carried out using an Edinburgh Instruments FLSP920 system equipped with a $450 \mathrm{~W}$ Xe lamp and a $60 \mathrm{~W}$ micro-second flash lamp as the excitation sources. All emission spectra were corrected for the detector response and the excitation spectra for the lamp profile. For lifetime measurements, a $60 \mathrm{~W}$ micro-second flash lamp, operating at a frequency of $100 \mathrm{~Hz}$ with a pulse duration of around 1-2 micro-seconds, was used.

\section{Results and discussion}

Before leaching, the NBS glass sample showed a broad XRD peak characteristic of amorphous nature (figure 1a). XRD patterns of pellets and powder samples of NBS glass after leaching are shown in figure $1 \mathrm{~b}$ and $\mathrm{c}$, respectively. These patterns confirm that the crystalline phases formed 

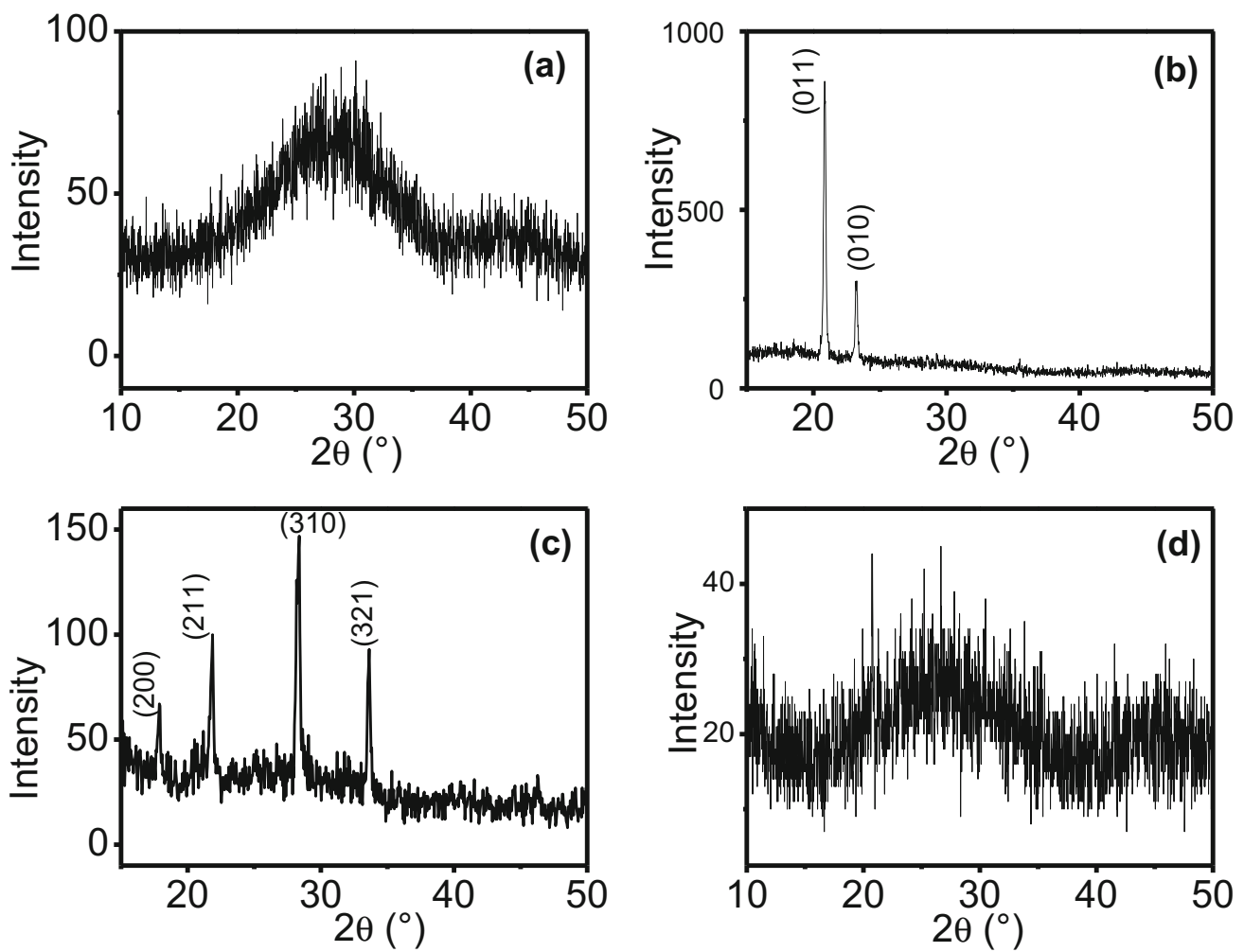

Figure 1. XRD patterns of NBS glass: (a) before leaching, (b) after pellet leaching and (c) after powder leaching. Corresponding patterns of ISG after pellet leaching is shown in (d).

upon leaching of the powder sample are quite different from those of pellets. Based on previous studies as well as the JCPDS data base, sharp XRD peaks arising from pellets and powder-leached samples have been attributed to the orthorhombic form of the silica [21] and aluminosilicate phase [22] known as zeolite $\mathrm{P}$, with the corresponding molecular formula $\mathrm{SiO}_{2}$ and $\mathrm{Na}_{6} \mathrm{Al}_{6} \mathrm{Si}_{10} \mathrm{O}_{32} \cdot 12 \mathrm{H}_{2} \mathrm{O}$, respectively. Generally, phases formed under hydrothermal conditions are sensitive to the temperature and the $\mathrm{pH}$ of the medium. The observed difference in the nature of the crystalline phase formed upon leaching can be explained by the difference in the extent of alkali ions leached from glass to medium (solution) during powder and pellet leaching experiments. As the surface area exposed will be significantly higher for the powder form of any sample compared to its pellet form, the concentration of $\mathrm{Na}^{+}$ions leached from the glass will be higher for the powder form compared to the pellet form. This leads to a higher $\mathrm{pH}$ value for the medium during powder leaching compared to the pellet leaching and explains the observed variation in the nature of the crystalline phase formed upon two different leaching conditions. Unlike the NBS glasses of the present study, the ISG sample does not undergo any sort of crystallization as can be seen from the XRD pattern shown in figure 2d. To investigate whether such differences in the leaching procedures also affect morphology of NBS glass, scanning electron microscopy (SEM) images were recorded from the samples and the results are discussed in the subsequent section.
Figure $2 \mathrm{a}$ and $\mathrm{b}$ shows the SEM images of the pristine NBS glass pellet and the pellet subjected to leaching for $192 \mathrm{~h}$ under hydrothermal conditions. The SEM image of the pristine glass sample shown in figure $2 \mathrm{a}$ confirms the existence of the homogeneous nature of glass without any phase segregation. Unlike this, after leaching, the image (figure 2b) clearly shows segregated phases, channels and irregularly shaped pits on the surface. The results are in conformity with the inferences drawn from the XRD results. It is noteworthy that the SEM image corresponding to the pellet leached sample is identical to that of the powder leached sample, reported earlier [19], although the corresponding XRD patterns are different. The SEM images of the ISG pellet sample before and after leaching are shown in figure $2 \mathrm{c}$ and $\mathrm{d}$. The images confirm the existence of the uniform and homogeneous nature of the sample before and after pellet leaching. In other words, there is no phase segregation or clustering occurring in the sample after pellet leaching under aggressive test conditions. Earlier powder leaching studies [19] also confirmed that the ISG sample does not show any phase segregation upon leaching under aggressive test conditions.

Leach rates corresponding to the $\mathrm{Si}, \mathrm{B}$ and $\mathrm{Na}$ species obtained from the pellet leaching studies of NBS glass are shown in table 1. For the purpose of comparison, the corresponding values for ISG are also given in the same table. Although powder leaching studies are available for these samples, a comparison of both powder and pellet leaching 

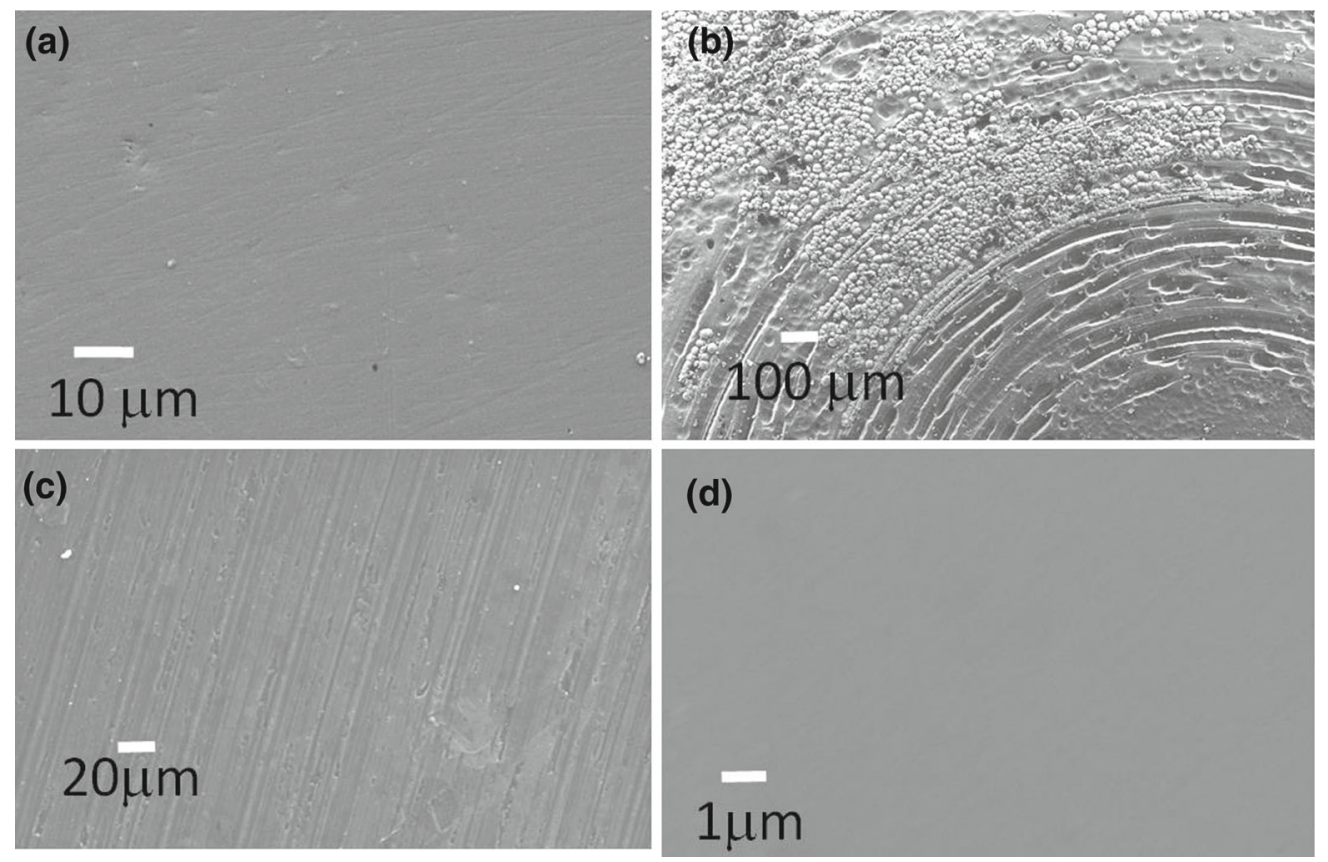

Figure 2. SEM images of the NBS glass pellet (a) before and (b) after leaching. Corresponding images of the ISG sample are shown in (c) and (d), respectively.

Table 1. Leach rate of glasses $\left(\mathrm{g} \mathrm{cm}^{-2} \mathrm{day}^{-1}\right)$.

\begin{tabular}{lcccc}
\hline Glass & $\mathrm{Na}$ & $\mathrm{B}$ & $\mathrm{Si}$ & $\mathrm{Ca}, \mathrm{Ti}, \mathrm{Al}, \mathrm{Zr}$ \\
\hline NBS & $3.11 \times 10^{-3}$ & $3.15 \times 10^{-3}$ & $1.57 \times 10^{-3}$ & BDL \\
ISG & $3.33 \times 10^{-4}$ & $1.66 \times 10^{-4}$ & $2.74 \times 10^{-4}$ & BDL \\
\hline
\end{tabular}

Normalized mass loss rate (normalized release rate) for different glass constituents of NBS and ISG samples in the pellet form. The values were calculated from analysis of leachate solution obtained after glass pellets were heated in an autoclave in demineralized water $(\mathrm{pH}=6.2)$ at $200^{\circ} \mathrm{C}$ under a pressure of $\sim 16$ bar for $192 \mathrm{~h}$.

All the values are average of triplicate results with relative standard deviation up to $2 \%$.

$\mathrm{BDL}$ indicates $\mathrm{Ba}=1.4 \times 10^{-6}, \mathrm{Al}=7.6 \times 10^{-6}, \mathrm{Ca}=3.45 \times 10^{-8}$ and $\mathrm{Ti}=8.6 \times 10^{-6} \mathrm{~g} \mathrm{~cm}^{-2} \mathrm{day}^{-1}$.

results is not attempted in the present study, as the surface area of the samples is different in both the cases. It is clear from table 1 that the pellet leach rates for $\mathrm{Na}, \mathrm{B}$ and $\mathrm{Si}$ are one order of magnitude higher for NBS glass compared to ISG. Other components like $\mathrm{Ca}^{2+}, \mathrm{Al}^{3+}, \mathrm{Ti}^{4+}$, etc., could not be detected from the leached solution for both the glass samples. The leach rate of boron species is nearly the same as that of $\mathrm{Na}^{+}$species in NBS glass, whereas it is higher than that of boron species corresponding to ISG. From these results, it is inferred that the leach rates of ISG are relatively less when compared with those of NBS glass. This has been attributed to the high content of glass formers like silica in ISG and the presence of $\mathrm{ZrO}_{2}$ as one of the modifiers. Although the presence of $\mathrm{SiO}_{2}$ and $\mathrm{ZrO}_{2}$ in the glass leads to the decrease in the leach rate associated with different glass constituents, glass formation temperature increases with the incorporation of such components. The higher the glass formation temperature, the higher will be the extent of corrosion associated with the process pot and/or furnaces which is detrimental to vitrification plants. To correlate the observed differences in the leaching properties of the above-mentioned glasses, TG-DTA, FTIR and luminescence studies were carried out and the results are described below.

Figure $3 \mathrm{a}$ and $\mathrm{b}$ shows DTA patterns of the NBS glass pellet before and after leaching. The unleached sample is characterized by an endothermic peak with an onset of around $550^{\circ} \mathrm{C}$ characteristic of the glass transition temperature (figure 3a). Unlike this, the leached NBS glass sample is characterized by three peaks around 100,220 and $550^{\circ} \mathrm{C}$ (figure 3b), which have been, respectively, attributed to the removal of physisorbed water, dehydration of hydroxy boron species (to form boron oxide/borate species) and melting of the $\mathrm{B}_{2} \mathrm{O}_{3}$ /borate phase. The DTA pattern shown in figure $3 \mathrm{~b}$ confirms that significant modifications occurred with the glass samples upon subjecting to pellet leaching. Unlike the NBS glass of the present study, the DTA pattern of ISG in figure 4 

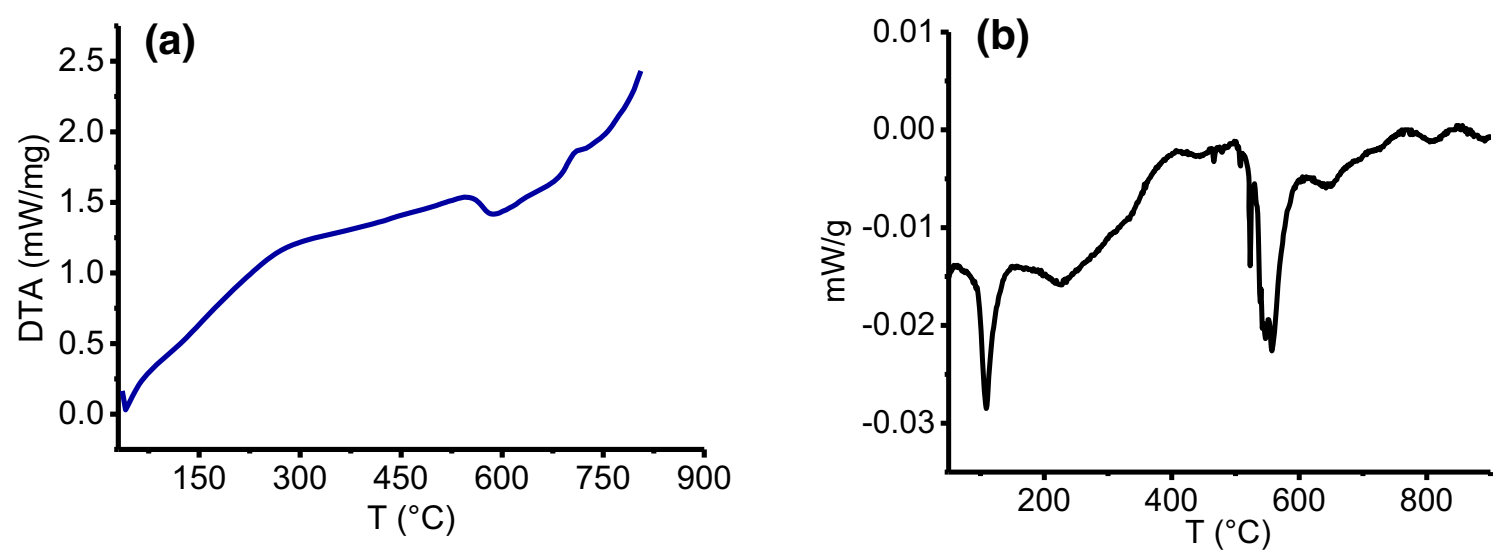

Figure 3. DTA patterns of (a) unleached and (b) leached NBS glass.

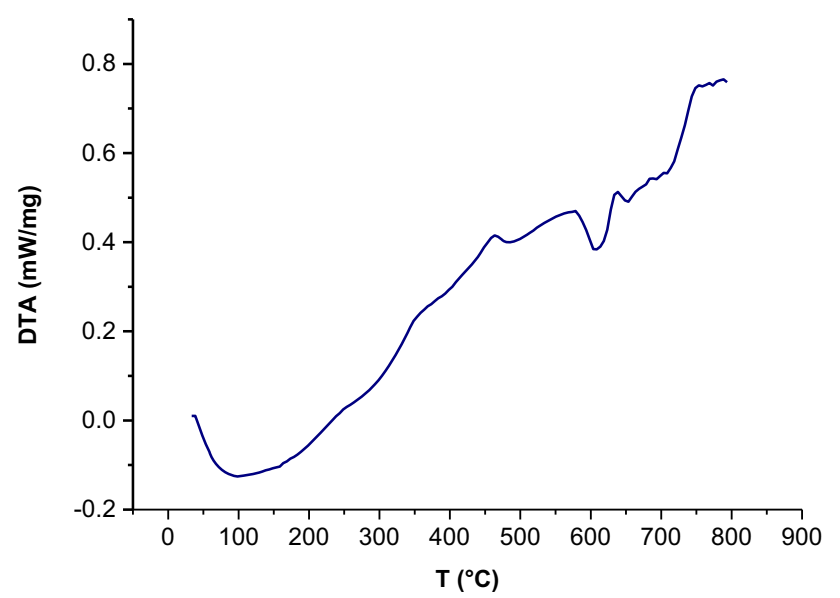

Figure 4. DTA patterns of ISG.

indicates a glass transition temperature of around $585^{\circ} \mathrm{C}$. No change was observed in the DTA pattern of ISG after leaching. The DTA results also confirm the improved stability of ISG against leaching compared to NBS glass. Drastic changes in the DTA pattern of NBS glass after leaching must be influenced by the structural network constituting the glass and this is confirmed by recording FTIR patterns of the glasses. The results are discussed in the following section.

Figure 5 shows the FTIR patterns of NBS glass and ISG before and after leaching. All glass samples are mainly characterized [20] by an intense peak around $1034 \mathrm{~cm}^{-1}$ along with less intense peaks around 1456 and $696 \mathrm{~cm}^{-1}$. For the NBS glass subjected to leaching, the line width of the peak at $1034 \mathrm{~cm}^{-1}$ decreases significantly as can be seen in figure 5 , although the peak maximum is nearly the same compared to the other glass samples. From earlier studies [15], the intense peak around $1034 \mathrm{~cm}^{-1}$ is attributed to the asymmetric stretching vibrations of the $\mathrm{Si}-\mathrm{O}-\mathrm{Si} / \mathrm{Si}-\mathrm{O}-\mathrm{B}$ linkages [23]. Symmetric stretching

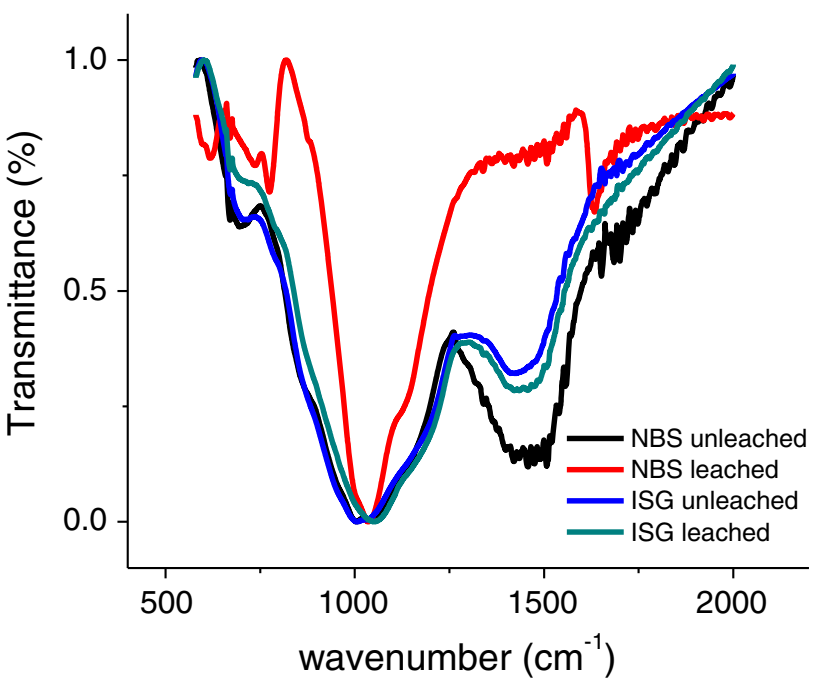

Figure 5. FTIR patterns of NBS and ISG samples before and after leaching.

vibrations corresponding to this mode appear around $696 \mathrm{~cm}^{-1}$. The peak appearing around $1456 \mathrm{~cm}^{-1}$ is due to the $\mathrm{B}-\mathrm{O}$ stretching vibrations of $\mathrm{BO}_{3}$ structural units in the glass [15]. For NBS glass, there is a significant reduction in the line width corresponding to vibrations of $\mathrm{Si}-\mathrm{O}-\mathrm{Si} / \mathrm{Si}-\mathrm{O}-\mathrm{B}$ linkages upon leaching as can be seen in figure 5. Significant reduction in the line width indicates reduction in strain (disorder) occurring with the glass network. This is possible when the extended borosilicate glass network undergoes alteration. For ISG, the line width remained nearly same before and after leaching, confirming that the glass network remains unaltered upon leaching. The results confirm that there is considerable reduction in the extent of networking in NBS glass upon leaching. It will be interesting to know whether such structural changes do have an effect on the photoluminescence properties of the glass samples and the same is discussed in the following section. 

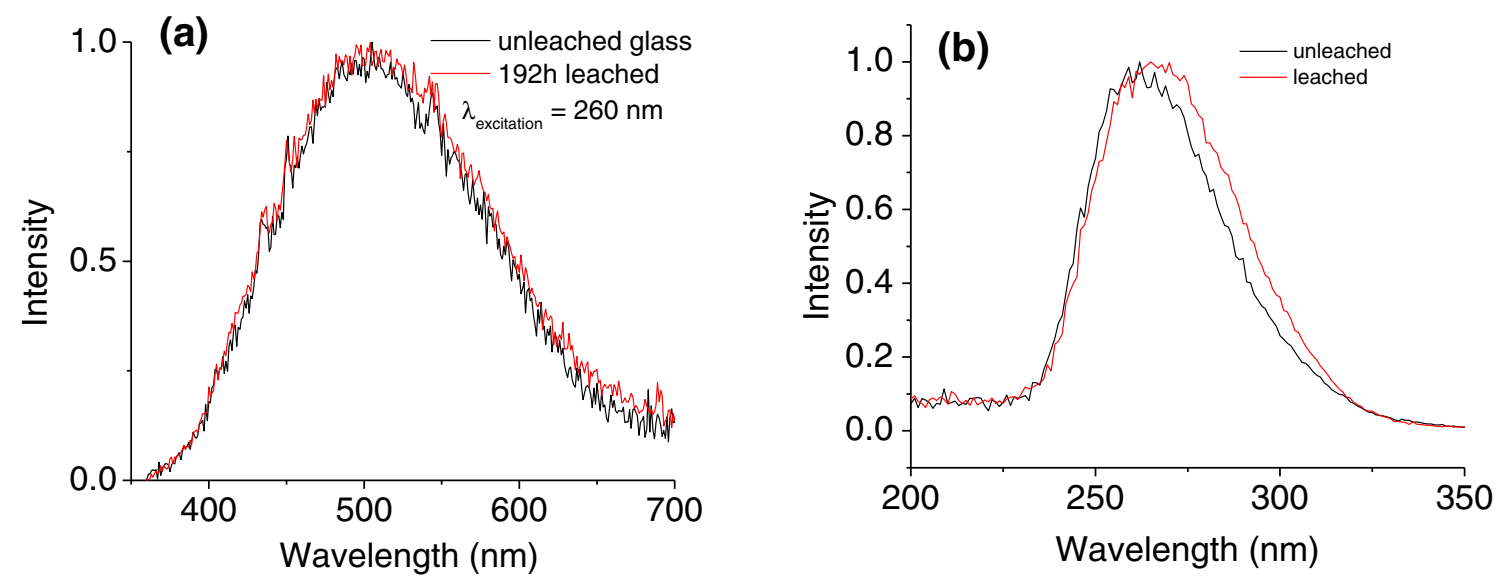

Figure 6. Emission spectra and (a) excitation spectra corresponding to $506 \mathrm{~nm}$ emission (b) from unleached and $192 \mathrm{~h}$ leached NBS glass samples. Excitation wavelength was $260 \mathrm{~nm}$.

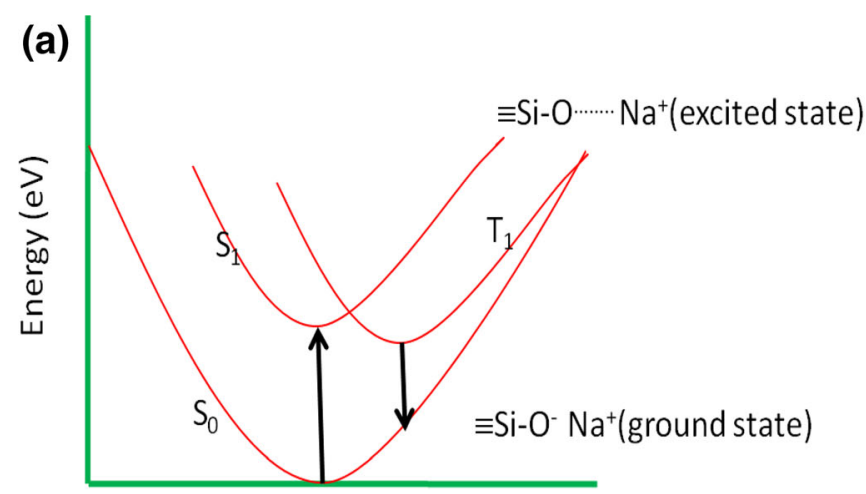

(b)

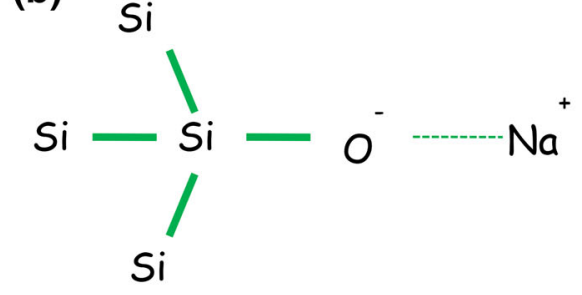

(c)
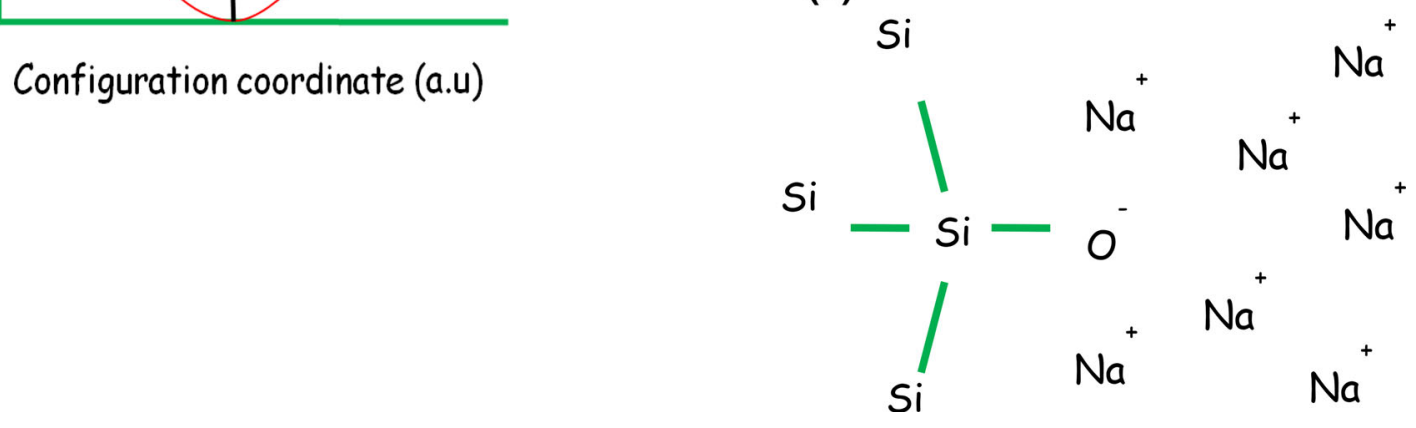

Figure 7. Schematic representation of (a) L-centre transitions, (b) structural units responsible for the ground state and (c) excited states of L-centre.

\subsection{Photoluminescence studies}

Figure 6 a shows the emission spectra of the NBS glass in the pellet form before and after leaching under hydrothermal conditions for $192 \mathrm{~h}$ at $200^{\circ} \mathrm{C}$. Emission spectra are identical to the leached and unleached glass samples and are characterized by a broad peak centred around $500 \mathrm{~nm}$ with tailing towards a higher wavelength region. Corresponding excitation spectra showed a wavelength maximum of around 260 $\mathrm{nm}$ as can be seen in figure 6b. Line shapes are similar for both emission and excitation spectra. The high value of the Stokes shift indicates that the excited state undergoes strong interaction with local environments in the glass. Furthermore, the excitation spectra of the leached sample are slightly redshifted with respect to that of the unleached sample, which further confirms the increased interaction in the excited state. Based on the reported luminescence studies of alkali silicate glasses [24,25], the peak around $500 \mathrm{~nm}$ is attributed to the recombination of electrons and holes associated with localized centres also known as the L-centres present in the glass. The fact that the emission spectra are not affected even after leaching, confirms that the emission occurs from the residual glass samples (leftover after leaching) and the leached products are non-luminescent. L-centres arise due 


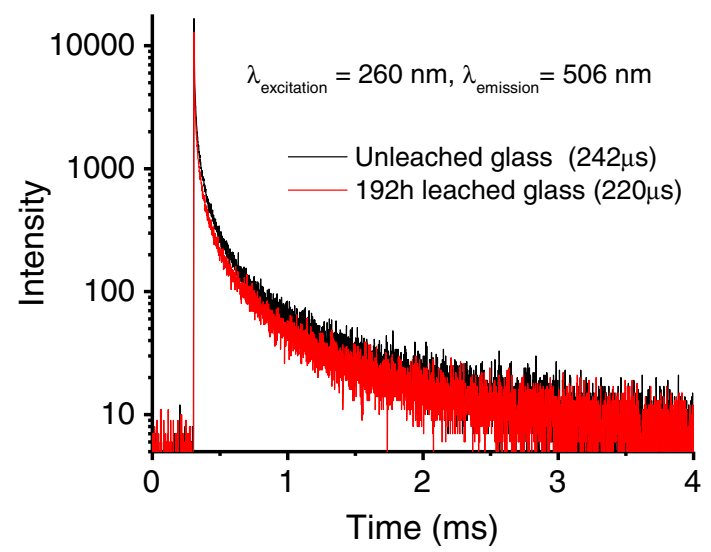

Figure 8. Decay curves corresponding to $500 \mathrm{~nm}$ emission from unleached and leached NBS glass samples.

to the presence of structural groupings of type $\mathrm{Si}-\mathrm{O}^{-} \mathrm{Na}^{+}$ and such linkages form localized states in sodium silicate glasses (example of a colour centre) [23]. The ground state of the L-centre corresponds to the ionic bonding between $\mathrm{O}^{-}$ and $\mathrm{Na}^{+}$ions (bonding state) and the excited state is formed by the transfer of one electron from the non-bridging oxygen atom to the $\mathrm{Na}^{+}$ion, resulting in the covalent bonding between $\mathrm{Na}^{0}$ and $\mathrm{O}$ atoms (anti-bonding state). The L-centre luminescence in sodium silicate glasses arises due to the transition between the anti-bonding and bonding states and is observed in the visible region $[24,25]$. This is schematically shown in figure 7 . L-centre luminescence from the sample is further confirmed by the decay curve corresponding to the emission from the samples as can be seen in figure 8 . Decay is found to be multi-exponential, suggesting the variation in the local environment around L-centres present in the samples. The average value of the lifetime is found to be $242 \mathrm{~ms}$ for the unleached and $220 \mathrm{~ms}$ for the leached samples. Lifetime values further confirm the L-centre emission from the glass. It will be interesting to know whether ISG also shows luminescent centres like the ones mentioned above and figure 9 shows the emission spectra of ISG before and after leaching. It is observed that the signal-to-noise ratio of the emission spectra corresponding to ISG is very poor when compared with that of NBS glass. The results suggest that the localized centres like $\mathrm{Si}-\mathrm{O}^{-} \mathrm{Na}^{+}$are present to a lesser extent in ISG compared to NBS glass. This is understandable from the composition of both the glass samples, namely, $\left(\mathrm{SiO}_{2}\right)_{0.477}\left(\mathrm{~B}_{2} \mathrm{O}_{3}\right)_{0.239}\left(\mathrm{Na}_{2} \mathrm{O}\right)_{0.170}\left(\mathrm{TiO}_{2}\right)_{0.023}(\mathrm{CaO})_{0.068}$ $\left(\mathrm{Al}_{2} \mathrm{O}_{3}\right)_{0.023}$ for NBS and $\left(\mathrm{SiO}_{2}\right)_{0.601}\left(\mathrm{~B}_{2} \mathrm{O}_{3}\right)_{0.160}\left(\mathrm{Na}_{2} \mathrm{O}\right)_{0.126}$ $(\mathrm{CaO})_{0.057}\left(\mathrm{Al}_{2} \mathrm{O}_{3}\right)_{0.038}\left(\mathrm{ZrO}_{2}\right)_{0.017}$ for ISG. For the NBS glass, the mole ratio of $\mathrm{Na}_{2} \mathrm{O}$ to $\mathrm{SiO}_{2}$ is 0.356 , whereas that in ISG is 0.209. A higher value of the $\mathrm{Na}_{2} \mathrm{O} / \mathrm{SiO}_{2}$ ratio leads to a large number of $\mathrm{Si}-\mathrm{O}^{-} \mathrm{Na}^{+}$linkages in the glass samples which leads to the increased intensity of L-centre emission from the NBS glass compared to ISG. This also accounts for the higher extent of leaching and network degradation/dissolution occurring with the NBS glass compared to ISG. It is interesting to

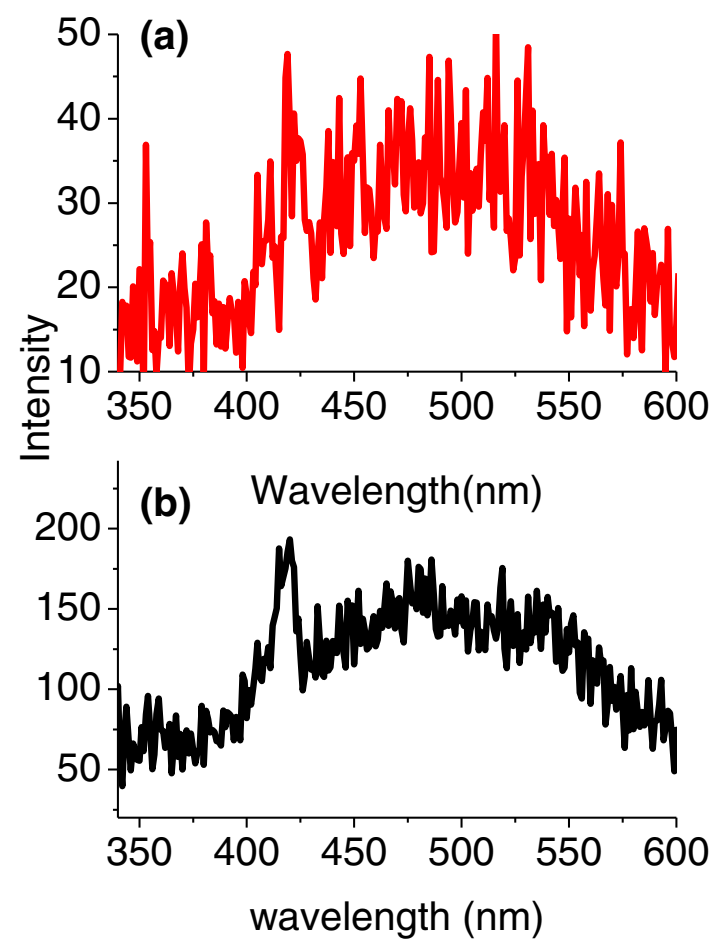

Figure 9. Emission spectrum from the ISG sample subjected to (a) before and (b) after leaching. Excitation wavelength was $260 \mathrm{~nm}$.

see that similar to NBS glass, the emission maximum and line shape are nearly the same for both leached and unleached ISG samples, suggesting that the local environment around the L-centre is nearly the same in both the glass compositions and glass network dissolution occurs upon leaching without affecting $\mathrm{Si}-\mathrm{O}^{-} \mathrm{Na}^{+}$linkages. As the emission spectra are too noisy for the ISG samples, decay curves could not be recorded from the samples.

From FTIR, DTA and luminescence studies, it is inferred that a significant number of $\mathrm{Si}-\mathrm{O}^{-} \mathrm{Na}^{+}$linkages are responsible for the increased extent of leaching from NBS glass compared to the ISG sample. The crystalline phase formed upon pellet leaching is found to be different from that of powder leaching and this is explained based on the higher extent of $\mathrm{Na}^{+}$ions leached out from the glass under aggressive test conditions.

\section{Conclusions}

Based on the detailed leaching and structural studies carried out on the powder and pellet samples of NBS glass, it is concluded that crystalline phases formed upon leaching under aggressive test conditions of NBS glass in the pellet and powder forms are different and this has been explained based on the extent of $\mathrm{Na}^{+}$ion leached out from the glass samples. Unlike NBS glass, ISG does not undergo any detectable change under aggressive test conditions in both powder and 
pellet forms. Techniques like DTA, FTIR and luminescence studies confirmed that significant network degradation occurs with NBS glass compared to the ISG sample upon leaching. These observations are expected because the glass former to modifier ratio is more in the case of ISG than NBS. These results will be useful to understand the mechanism of leaching of glass at higher temperatures in the monolithic form.

\section{References}

[1] Ojovan M I and Karlina O K 1992 Radiochim. Acta 3497

[2] SRNL Report 2012 Letter report on compositional measurements of common simple glass, milestone: M4FT12SR0307084

[3] Hill M D and Grimwood P D 1978 NRPB R-69

[4] Hill M D 1979 NRPB Report R-86

[5] Lutze W and Ewing R C 1988 Radioactive waste forms for the future (North-Holland: Amsterdam) p 1

[6] Ojovan M I, Pankov A and Lee W E 2006 J. Nucl. Mater. 358 57

[7] Ojovan M I and Lee W E 2011 Metall. Mater. Trans. A 42837

[8] Wu P, Zhang C, Xu H, Huang D, Xu B and Jiang D 2011 Adv. Mater. Res. 177466

[9] Gin S, Jollivet P, Fournier M, Angeli F, Frugier P and Charpentier T 2015 Nat. Commun. 66360

[10] Iseghem P V, Aertsens M, Gin S, Deneele D, Grambow B, Strachan D et al 2009 Ceram. Trans. 207115
[11] Vienna J D, Ryan J V, Gin S and Inagaki Y 2013 Int. J. Appl. Glass Sci. 4283

[12] Gin S, Beaudoux X, Angéli F, Jégou C and Godon N 2012 J. Non-Cryst. Solids $\mathbf{3 5 8} 2559$

[13] Hasanuzzaman A R M, Rafferty A and Olabi A G 2014 Ceram. Int. 40581

[14] Mishra R K, Sudarsan V, Kaushik C P, Raj K, Vatsa R K, Body M et al 2009 J. Non-Cryst. Solids 355414

[15] Banerjee D, Sudarsan V, Joseph A and Das D $2010 \mathrm{~J}$. Am. Ceram. Soc. 933252

[16] Banerjee D, Wattal P K, Sudarsan V and Das D 2013 Phys. Chem. Glasses: Eur. J. Glass Sci. Technol. 54157

[17] Gin S, Abdelous A, Criscenti L J, Ebert W L, Ferrand K, Geisler T et al 2013 Mater. Today 16243

[18] Gin S, Jollivet P, Fournier M, Berthon C, Wang Z, Mitroshkov A et al 2015 Geochim. Cosmochim. Acta 15 168

[19] Thorat V S, Mishra R K, Sudarsan V, Kumar A, Vatsa R K, Kaushik C P et al 2016 J. Am. Ceram. Soc. 993251

[20] Mishra R K, Sudarsan V, Jain S, Kaushik C P, Vatsa R K and Tyagi A K 2013 J. Am. Ceram. Soc. 97427

[21] PC-PDF card no. 82-1570

[22] PC-PDF card no. 74-1787

[23] Mishra R K, Sudarsan V, Kaushik C P, Raj K, Kulshreshtha S K and Tyagi A K 2007 J. Non-Cryst. Solids 353 1612

[24] Arbuzov V I, Vitol I K, Grabovskis V Y and Tolstoi M N 1985 Sov. J. Glass Phys. Chem. 11400

[25] Shrikhande V K, Sudarsan V, Kothiyal G P and Kulshreshtha S K 2007 J. Non-Cryst. Solids 3531341 